\title{
Spectral Study of Modified Humic Acids from Lignite
}

\author{
Sergey Zherebtsov ${ }^{1,}$, Natalya Malyshenko ${ }^{1}$, Ludmila Bryukhovetskaya $^{1}$, and Zinfer \\ Ismagilov $^{1}$ \\ ${ }^{1}$ Federal Research Center of Coal and Coal Chemistry, 65000018 Sovetskii av., Kemerovo, Russia
}

\begin{abstract}
The IR-Fourier, ESR and solid-state ${ }^{13} \mathrm{C}$ NMR analysis are used for investigation of unmodified and modified humic acids obtained from Tisul lignite (the Kansko-Achinsk Basin). Treatment with Hydrogen peroxide used for modification of humic acids and it changes the functionalgroup composition of the humic acids and increases the sorptional capacity.
\end{abstract}

\section{Introduction}

The structure of humic acids reflects the material from which they are derived [1-4]. The reactivity of humic acids depends on the presence of different functional groups and it reflects the content of aromatic conjugates and degree of condensation. Chemical modification may change the functional composition of the humic acids.

Humic acids derived from alkylated and debitumenized lignite and peat are characterized by an elevated content of aromatic and phenolic components, as noted in [5-7]. It is important to establish the relation between the composition, structure, and proper- ties of the humic acids, in order to understand their behavior in nature and in technological processes. That, in turn, will permit their more effective use.

The applications of humic acids depend on their chemical composition and properties. One major application is sorbent production [8,9]. The presence of ion-exchange carboxyl groups and phenolic hydroxyls, as well as electron-donor functional groups, facilitates ion exchange in complex formation and creates prospects for the separation and extraction of metal cations from various media and for the purification of wastewater and industrial water.

Purposeful chemical modification may increase the content of the desired functional groups and thereby improve the sorptional characteristics of the humic acids. The sorption of zinc cations by humic acids derived from lignite and naturally oxidized coal from the Tisul field is due to ion exchange, as shown in [10]. Modification by hydrogen peroxide increases the content of carboxyl groups, whose protons participate in ion exchange, and therefore expands the sorptional capacity of the humic acids [10].

In the present work, we investigate the functional group composition of humic acids derived from lignite after modification by hydrogen peroxide.

* Corresponding author: sizh@yandex.ru 


\section{Experimental Method}

We prepared the humic acids from Tisul lignite (from the Kansko-Achinsk Basin), by the method in [11]. That method is based on treating lignite with potassium hydroxide to produce solutions of potassium humates, to which $10 \%$ hydrochloric acid is added. The humic acid deposits are filtered out, washed in distilled water to specified $\mathrm{pH}$, and dried at $70^{\circ} \mathrm{C}$. Table 1 . presents the characteristics of the initial samples

Table 1. Technical and elementary analysis of the samples, $\%$.

\begin{tabular}{|c|c|c|c|c|c|c|c|}
\hline Sample & $\boldsymbol{W}^{\boldsymbol{a}}$ & $\boldsymbol{A}^{\boldsymbol{d}}$ & $\boldsymbol{V}^{\boldsymbol{d a f}}$ & $\mathbf{C}^{\boldsymbol{d a f}}$ & $\mathbf{H}^{\boldsymbol{d a f}}$ & $\begin{array}{c}(\mathbf{O}+\mathbf{N}+\mathbf{S})^{\boldsymbol{d a f}} \\
(\text { as a difference) }\end{array}$ & (HA) $\boldsymbol{t}^{\text {daf }}$ \\
\hline Coal & 8.04 & 6.11 & 48.14 & 64.34 & 4.69 & 30.97 & 26.88 \\
\hline $\begin{array}{c}\text { Humic } \\
\text { acids }\end{array}$ & 4.97 & 4.01 & - & 60.84 & 4.18 & 36.07 & - \\
\hline
\end{tabular}

Here $d a f$ denotes a dry ash-free state. (HA) $t_{t}^{d a f}$ is the yield of humic acids.

The humic acids are modified by means of hydrogen peroxide (concentration $32.5 \%$ ) to obtain constant volume of potassium-humate solutions of equal concentration, with mixing for a specified time, and then adding hydrochloric acid. The deposits are filtered out, washed in distilled water to specified $\mathrm{pH}$, and dried at $70^{\circ} \mathrm{C}$ to constant weight.

High-resolution solid-state ${ }^{13} \mathrm{C}$ NMR spectra are recorded on a Bruker Avance III $300 \mathrm{~W}$ instrument at $75 \mathrm{MHz}$, with rotation of the samples at $5 \mathrm{kHz}$.

IR spectra are recorded on an Infralyum-FT 801 Fourier-transformation spectrometer, by means of tablets with $\mathrm{KBr}$.

The ESR samples are recorded at room temperature on a Bruker EMX-m40X ESR spectrometer at $9.86 \mathrm{GHz}$. The ESR spectra of all the samples are recorded in identical conditions: power 1.8-1.9 mW; modulation frequency100 kHz. To determine the quantity of organic paramagnetic centers, $\mathrm{Mn}^{2+}$ ions in magnesium oxide $\mathrm{MgO}$ are chosen as the standard. The characteristics of the ESR spectra are calculated by means of Bruker Win EPR software.

\section{Results and Discussion}

Humic acids are characterized by typical absorption bands in the IR spectra; that is consistent with the results in $[12,13]$. In Fig. 1, we show the IR spectrum of unmodified humic acids and humic acids modified with hydrogen peroxide.

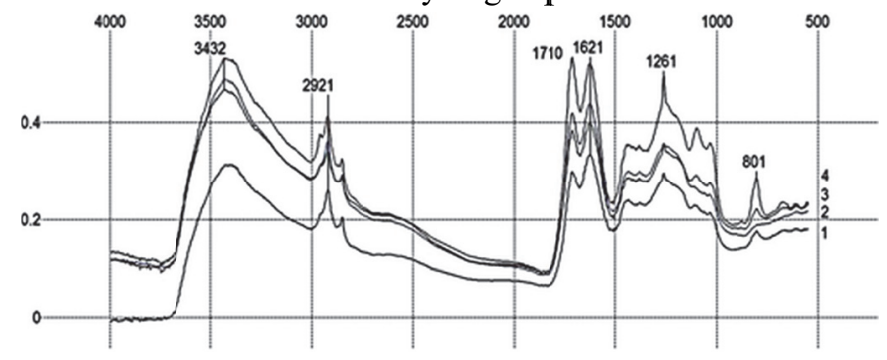


Fig. 1. IR spectra: unmodified humic acids; (2-4) humic acids modified with 5, 10, and $15 \mathrm{~mL}$ of hydrogen peroxide, respectively.

For all the humic acids obtained, bands of different intensity appear in the range 1720$1710 \mathrm{~cm}^{-1}$, corresponding to valence vibrations of the $\mathrm{C}=\mathrm{O}$ bond of the humic acids' carboxyl groups. We see that modification by hydrogen peroxide increases the intensity of the bands corresponding to the $\mathrm{C}=\mathrm{O}$ bond of the humic acids' carbonyl groups $\left(1710 \mathrm{~cm}^{-1}\right)$; the carbonyl groups of the primary amides and the conjugate $\mathrm{C}=\mathrm{C}$ bonds $\left(1620 \mathrm{~cm}^{-1}\right)$; the $\mathrm{C}-\mathrm{O}$ bonds of carboxylic acids complex esters, the $\mathrm{O}-\mathrm{H}$ bonds of phenols and carboxyl groups $\left(1260 \mathrm{~cm}^{-1}\right)$; the $\mathrm{C}-\mathrm{O}$ bonds of alcohols and esters (1100-1030 $\left.\mathrm{cm}^{-1}\right)$; and hydrogen-bonded $\mathrm{OH}$ groups $\left(3400 \mathrm{~cm}^{-1}\right)$. Table 2 presents the ${ }^{13} \mathrm{C}$ NMR and ESR data: the integral intensities of the spectral regions and the para-magnetic centers of the humic-acid samples.

Table 2. Integral intensities of the spectral regions in the ${ }^{13} \mathrm{C}$ NMR spectra (\%) and paramagnetic centers in the ESR spectra of the samples.

\begin{tabular}{|c|c|c|c|c|c|c|c|c|}
\hline \multirow[b]{2}{*}{ Sample* } & \multicolumn{7}{|c|}{ Chemical shift, ppm } & \multirow{2}{*}{$\begin{array}{l}\text { PMC } \\
\times 10^{-18}, \\
\text { spin/g }\end{array}$} \\
\hline & $\begin{array}{c}220- \\
187 \\
C=O\end{array}$ & $\begin{array}{c}187- \\
165 \\
\text { СООН }\end{array}$ & $\begin{array}{c}165- \\
145 \\
C_{\text {ar-O }}\end{array}$ & $\begin{array}{c}145- \\
108 \\
C_{a r}\end{array}$ & $\begin{array}{c}\text { 108-90 } \\
\text { CO-alk- } \\
\text { O }\end{array}$ & $\begin{array}{c}90-48 \\
C_{\text {alk }}-O\end{array}$ & $\begin{array}{l}48-5 \\
C_{\text {alk }}\end{array}$ & \\
\hline Humic acids Humic & 1.04 & 5.83 & 10.93 & 19.22 & 0 & 9.08 & 53.87 & 8.92 \\
\hline acids (5) Humic & 1.10 & 6.12 & 10.01 & 18.90 & 0 & 11.68 & 52.19 & 7.18 \\
\hline acids (10) Humic & 1.16 & 6.27 & 10.00 & 18.63 & 0 & 11.97 & 51.97 & 6.42 \\
\hline acids (15) & 1.24 & 6.35 & 9.98 & 18.86 & 0 & 11.96 & 51.61 & 5.13 \\
\hline
\end{tabular}

* The figures in parentheses in the sample notation indicate the quantity of $\mathrm{H}_{2} \mathrm{O}_{2}(\mathrm{~mL})$ used in modification; PMC, paramagnetic centers.

We see that modification by hydrogen peroxide increases the content of carbonyl $\mathrm{C}=\mathrm{O}$, carboxyl $\mathrm{COOH}$ groups, and groups containing oxygen with an alkyl carbon atom $\mathrm{C}_{\mathrm{alk}}-\mathrm{O}$. Correspondingly, the content of $\mathrm{C}_{\mathrm{ar}}, \mathrm{C}_{\mathrm{ar}}-\mathrm{O}$, and $\mathrm{C}_{\mathrm{alk}}$ is reduced. Comparing the IR and NMR data, we find that they are generally consistent.

$\mathrm{PMC} 10^{18}, \mathrm{spin} / \mathrm{g}$

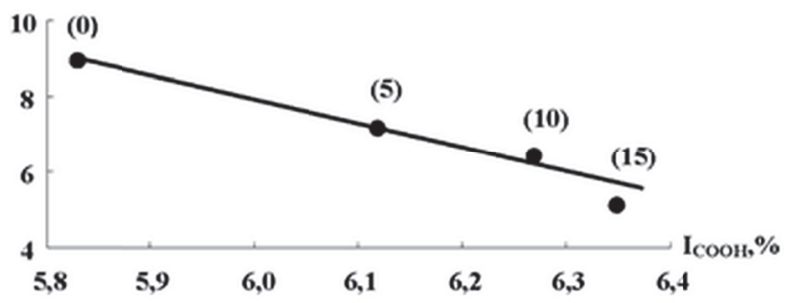


Fig. 2. Dependence of the concentration of paramagnetic centers (PMC) in the humic acids on the intensity of the carboxyl groups with modification by different quantities of hydrogen peroxide (shown on the curves, $\mathrm{ml}$ ).

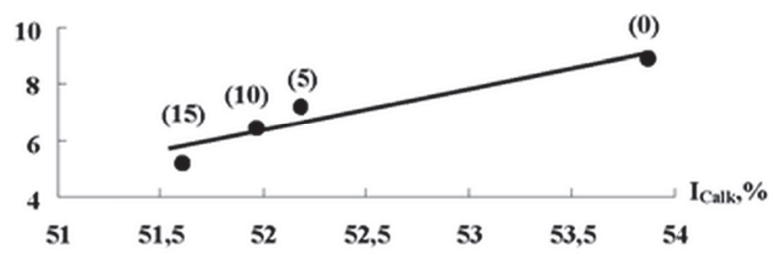

Fig. 3. Dependence of the concentration of paramagnetic centers (PMC) in the humic acids on the intensity of the Calk groups with modification by different quantities of hydrogen peroxide (shown on the curves, $\mathrm{ml}$ ).

The ESR spectra are recorded with $g=2.003-2.004$. That corresponds to the radicals of organic compounds [14]. The signals from the samples are symmetric or slightly asymmetric; this is typical of coal and solid polyaromatic compounds of quinoid type [15]. Modified and unmodified humic acids are characterized by narrow lines corresponding to organic paramagnetic centers. That may indicate a high content of polyconjugate aromatic structures.

Increasing the hydrogen-peroxide concentration on modification reduces the content of organic paramagnetic centers (Table 2), to an extent that depends on the functionalgroup composition of the humic acids. In Fig. 2, we see that, with increase in the con- tent of carboxyl groups (according to NMR data) during modification, the concentration of paramagnetic centers declines. Inverse proportionality is also seen for the carbonyl groups $\mathrm{C}=\mathrm{O}$ and the $\mathrm{C}_{\mathrm{alk}}-\mathrm{O}$ groups.

At the same time, the decrease in the $\mathrm{C}_{\mathrm{ar}}-\mathrm{O}, \mathrm{C}_{\mathrm{ar}}$, and $\mathrm{C}_{\mathrm{alk}}$ concentrations during modification by hydro- gen peroxide leads to proportional decrease in the concentration of organic paramagnetic centers. In Fig. 3, as an example, we show the concentration of paramagnetic centers as a function of the $\mathrm{C}_{\mathrm{alk}}$ content.

The presence of paramagnetic centers in the humic acids may be due to free radicals. In modification by hydrogen peroxide, the decrease in aromatic content (Table 2) lowers the content of free radicals [16]. In addition, hydrogen peroxide is a source of OH radicals and oxygen and hence may lead to the destruction of organic radicals and may facilitate the appearance of new functional groups [17-20]. The change in composition of the humic acids, with increase in the content of oxygen-bearing groups, may be attributed to oxidative reactions with the participation of hydrogen peroxide. We see from Table 2 that reducing the content of some functional groups increases the content of others. For example, the $\mathrm{C}_{\text {alk }}$ content declines, while the $\mathrm{C}_{\text {alk }}-\mathrm{O}$ content increases.

\section{Conclusion}

Modification of the humic acids derived from lignite and naturally oxidized coal by hydrogen peroxide increases sorptional capacity in the sorption of zinc cations by a factor of 2-4 in comparison with unmodified humic acids.

By increasing of the content of various oxygen containing functional groups the expansion of sorptional capacity of humic acids can be achieved with respect to various cations, by both ion exchange and formation of complexes. 


\section{References}

1. I.V. Aleksandrova, Pochvov. 12, 47-51 (1993)

2. T.A. Kukharenko, Lignite and Coal Oxidized in the Earth Layers (Moscow, Nedra, 1972)

3. I.D. Komissarov, I.N. Strel'tsova, Influence of the extraction method of humic acids from the raw material on chemical composition of obtained preparations, in Guminovye preparaty (Humic Preparations) (Tyumen, Tyumen. S-kh. Inst.)

4. N.V. Yudina, V.I. Tikhova, Khim. Rastit. Syr'ya, 1, 93-96 (2003)

5. L.G. Sivakova, S.I. Zherebtsov, O.V. Smotrina, Solid Fuel Chem. 39:5, 20-26 (2005)

6. S.I. Zherebtsov, Yu.V. Musin, A.I. Moiseev, Khim. Rastit. Syr’ya, 2, 125-130 (2009)

7. S.I. Zherebtsov, Z.R. Ismagilov, Solid Fuel Chem. 46:6, 339-351 (2012)

8. J.C. Lobartini, K.H. Tan, J.A. Rema, Sci. Total Environ. 113:1, 1 (1992)

9. N.V. Malyshenko, S.I. Zherebtsov, O.V. Smotrina, L.V. Bryukhovetskaya, Z.R. Ismagilov, Khim. Int. Ust. Razvit. 23:4, 451-457 (2015)

10. E.M. Taits, Methods of Analysis and Tests of Coal, (Moscow, Nedra, 1983) 
